\title{
A STUDY OF MICROSTRUCTURE AND FATIGUE BEHAVIOUR OF A3003 ALLOY
}

\author{
${ }^{1}$ Jan ŠKODA, ${ }^{1}$ Monika LOSERTOVÁ, ${ }^{1}$ Kateřina KONEČNÁ, ${ }^{2}$ František FOJTÍK, ${ }^{3}$ Petr CZYŽ \\ ${ }^{1}$ VSB - Technical University of Ostrava, Faculty of Materials Science and Technology, Ostrava, \\ Czech Republic, EU, jan.skoda@vsb.cz \\ ${ }^{2}$ VSB - Technical University of Ostrava, Faculty of Mechanical Engineering, Ostrava, Czech Republic, EU, \\ ${ }^{3}$ Hanon Systems Autopal s.r.o., NovýJičín, Czech Republic, EU
}

https://doi.org/10.37904/metal.2021.4262

\begin{abstract}
A study of A3003 aluminium alloy in $\mathrm{H} 12$ temper regarding microstructure analysis, tensile testing, fatigue loading and fractography of fracture surfaces was carried out. Specimens were cyclic loaded at five stress amplitude levels of $62,68,70,72$ and $76 \mathrm{MPa}$ so that the results for both the low cycle fatigue and high cycle fatigue are obtained. During loading of the specimens at the highest stress amplitude the specimens resembled quasi-static fracture with necking usually seen in tensile testing. In our case, the stress amplitude of $72 \mathrm{MPa}$ can be considered transient as the failure went from quasi-static fracture to fracture with typical signs of fatigue. The $68 \mathrm{MPa}$ stress amplitude appears as a transition from LCF to HCF. Testing at the lowest stress amplitude was stopped after $10^{7}$ cycles without failure of the material so it can be regarded as fatigue limit for this alloy. Wrought microstructure was observed using optical microscopy and present phases were identified by EDX analysis as $\mathrm{Al}_{6} \mathrm{FeMn}$ and $\alpha-\mathrm{Al}_{12}(\mathrm{Fe}, \mathrm{Mn})_{3} \mathrm{Si}$. The microstructure of $\mathrm{H} 12$ temper was compared with the same alloy in $\mathrm{F}$ state.
\end{abstract}

Keywords: Low cycle fatigue, high cycle fatigue, A3003, fracture, Al-Mn

\section{INTRODUCTION}

Al-Mn based aluminium alloys are widely used throughout the industry. They are not suitable for highly stressed components as their main advantages are good formability, excellent corrosion resistance and specific strength rather than ultimate strength. In automotive industry, these alloys are mostly used for components in air conditioning as pipelines, condensers, containers, heat shields etc. With growing demand on performance of automobiles, the request for cooling also grows. Switching form internal combustion engines to electrical engines does not decrease the needs for effective cooling of the components and aluminium alloys are considered very effective solution with good cost, low weight and good possibilities for recycling but also with a lot of space for further research regarding their mechanical properties and especially fatigue properties. This study was focused on fatigue behaviour of the A3003-H12 alloy and fracture surfaces evaluation with regard to the number of loading cycles. The microstructure of the specimens was compared with the same alloy in $\mathrm{F}$ temper. Unlike $\mathrm{H} 12$ temper that describes work hardened to quarter hard and not annealed stage, $\mathrm{F}$ temper is "semi-finished" (otherwise as fabricated) stage with no property limits specified.

\section{METHODOLOGY \& EXPERIMENTAL}

The investigation included microstructure analysis, phase analysis, tensile testing, fatigue testing and fractographic study of the fracture surfaces after loading with aim to evaluate fatigue behaviour of the alloy in H12 temper, to compare the fracture surfaces after low cycle fatigue (LCF) and high cycle fatigue (HCF). The alloy in rod shaped specimens was supplied by Hanon Systems Autopal s.r.o. company. In total 5 polished specimens of $60 \mathrm{~mm}$ overall length, with $30 \mathrm{~mm}$ working length and $5 \mathrm{~mm}$ working diameter were prepared for 
the tensile testing and 14 polished specimens with $100 \mathrm{~mm}$ overall length, $50 \mathrm{~mm}$ working length and $6 \mathrm{~mm}$ working diameter for fatigue testing. Fatigue loading was carried out using servo-hydraulic single axis pulsator INOVA FU-63-930-V1 equipped with PC with TestControl_FU63 software. Tests were performed in load control mode using symmetric cycle at 5 levels of stress amplitude $-62,68,70,72$ and $76 \mathrm{MPa}$ to obtain results for both low cycle fatigue (LCF) and high cycle fatigue (HCF) [1]. The study of fracture surfaces after tensile testing and after cyclic loading was performed using JEOL JSM-649OLV scanning electron microscope (SEM) equipped with OXFORD INSTRUMENTS INCA $x$-act tool for EDX microanalysis. Microstructure analysis was carried out on selected specimens using Olympus GX51 optical microscope (OM) with DP1 digital camera. Grain shape and size were showed after electrolytic colour etching in a solution composed of $5 \mathrm{ml}$ $48 \% \mathrm{HBF}_{4}$ and $200 \mathrm{ml} \mathrm{H}_{2} \mathrm{O}$ using Struers Lectropol-5 device.

\section{RESULTS AND DISCUSSION}

Selected specimens were subjected to the microstructure and phase analysis using both OM and SEM. When comparing the longitudinal cuts of the tested specimens, small phases elongated and oriented in the forming direction can be seen for both $\mathrm{H} 12$ and F tempers (Figure 1a and Figure 1c). The cross sections of the specimens show similar results with phases and grains having in most cases approximately equiaxed shape (Figures 1b and 1d).
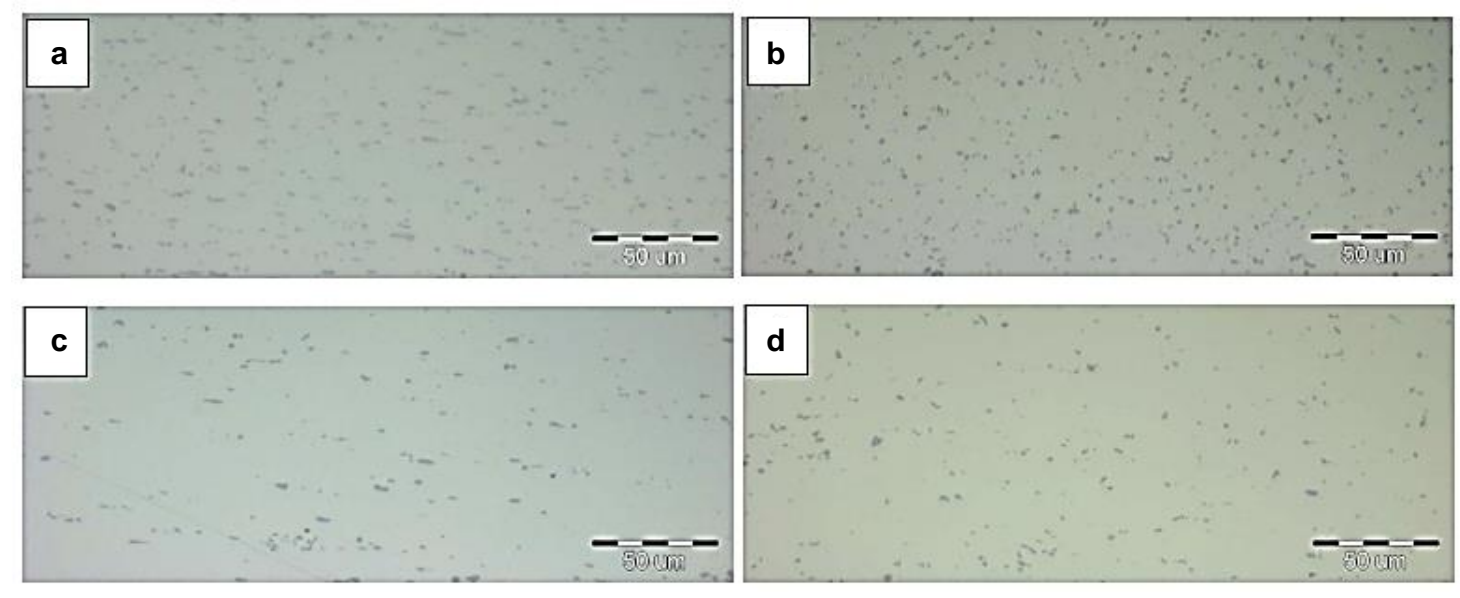

d

Figure 1 Microstructure of the specimens: a) longitudinal section of $\mathrm{H} 12$ temper, b) cross section of $\mathrm{H} 12$ temper, $c$ ) longitudinal section of $F$ temper, $d$ ) cross section of $F$ temper

The $\mathrm{F}$ temper contains fine particles of the similar size to that in $\mathrm{H} 12$ temper, but their distribution seems to be denser for the $\mathrm{H} 12$ temper. The phases observed were analysed using EDX analysis which confirmed the presence of $\alpha-\mathrm{Al}_{12}(\mathrm{Fe}, \mathrm{Mn})_{3} \mathrm{Si}$ and $\mathrm{Al}_{6}(\mathrm{Fe}, \mathrm{Mn})$ particles. The distribution of the phases can be controlled by alloy composition and heat treatment so called "6 to alpha" transformation [2, 3], which supports growth of the $\alpha$ $\mathrm{Al}_{12}(\mathrm{Fe}, \mathrm{Mn})_{3} \mathrm{Si}$ phase with higher strength, while the $\mathrm{Al}_{6}(\mathrm{Fe}, \mathrm{Mn})$ particles dissolve. Complete dissolution of the phases mentioned is very complicated due to danger of melting at higher annealing temperatures [4]. Both phases can affect recrystallisation and precipitation processes and through of this fatigue resistance of the alloy. Finding detailed information about the effects of the phases mentioned above on fatigue behaviour of the alloy is very difficult. When looking at OM images of colour etched samples, it can be clearly seen that the grains have been elongated in the direction of forming as mentioned before (Figures 2a, 3a). The $F$ temper shows much more profound deformation of the grains, which can be attributed to the fact, that recrystallisation annealing was not applied and the grains remained in deformed state (Figures $\mathbf{3 a}, \mathbf{3 b}$ ). We can also observe differences in size of the grains in the $\mathrm{H} 12$ temper (Figure $\mathbf{2 b}$ ). The difference can be caused by thermomechanical history of the $\mathrm{H} 12$ temper and possible dynamic recrystallisation processes occurring during extrusion [5]. 


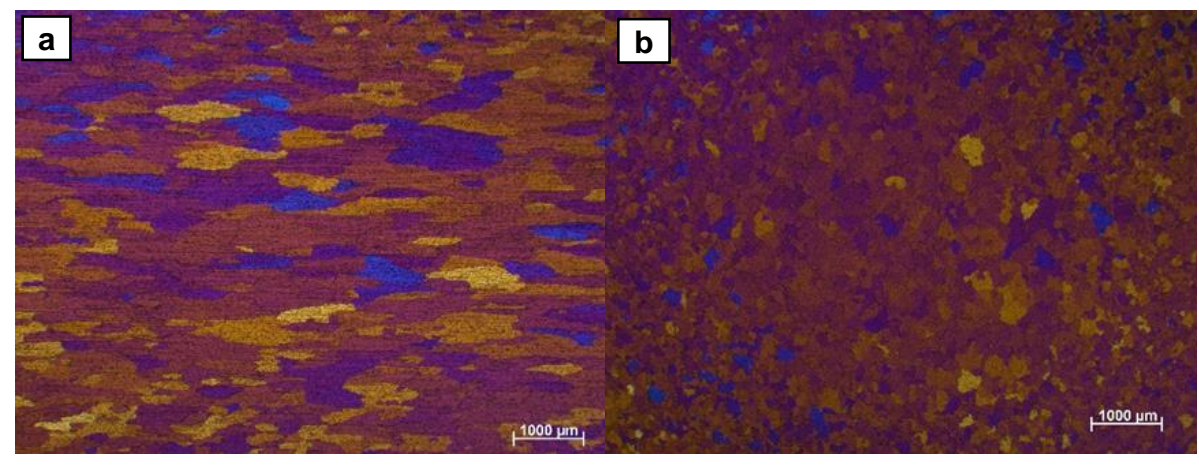

Figure 2 Colour etched microstructure of H12 temper: a) longitudinal, b) cross section

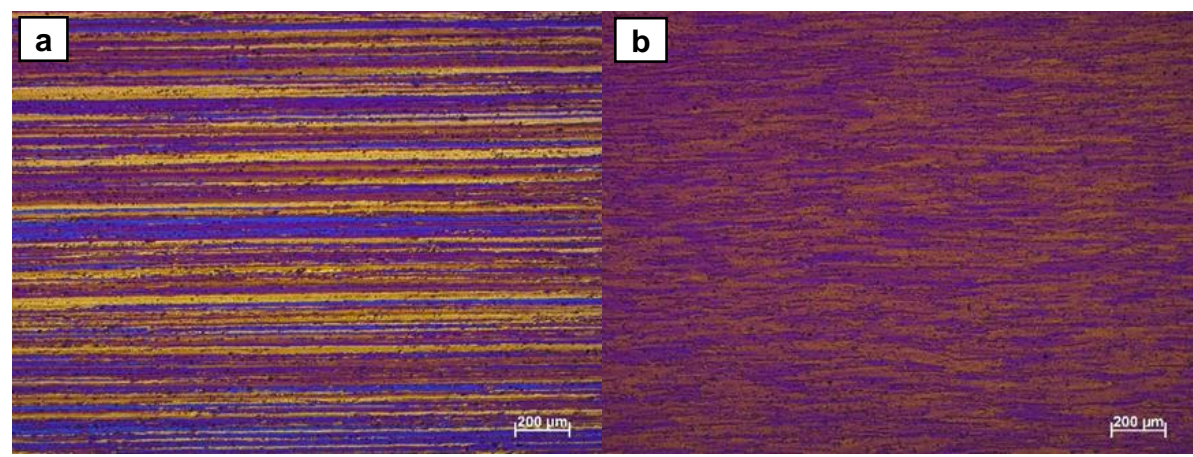

Figure 3 Colour etched microstructure of $F$ temper: a) longitudinal, b) cross section

The yield strength $R_{p 0,2}$ and ultimate tensile strength $R_{m}$ obtained by tensile testing (Table 1) are within the specifications of the A3003 alloy [6] with approximate yield strength of $117 \mathrm{MPa}$ and ultimate tensile strength of $123 \mathrm{MPa}$. Low difference between $R_{p 0,2}$ and $R_{m}$ corresponds with the $\mathrm{H} 12$ temper industrial data sheets.

Table 1 Results of tensile testing for A3003-H12 samples

\begin{tabular}{|c|c|c|}
\hline Sample & $\boldsymbol{R}_{\mathbf{p 0 . 2}}(\mathrm{MPa})$ & $\boldsymbol{R}_{\boldsymbol{m}}(\mathrm{MPa})$ \\
\hline 1 & 116 & 123 \\
\hline 2 & 117 & 123 \\
\hline 3 & 121 & 124 \\
\hline 4 & 118 & 123 \\
\hline 5 & 117 & 123 \\
\hline Average value & $118 \pm 1.9$ & $123 \pm 0.4$ \\
\hline
\end{tabular}

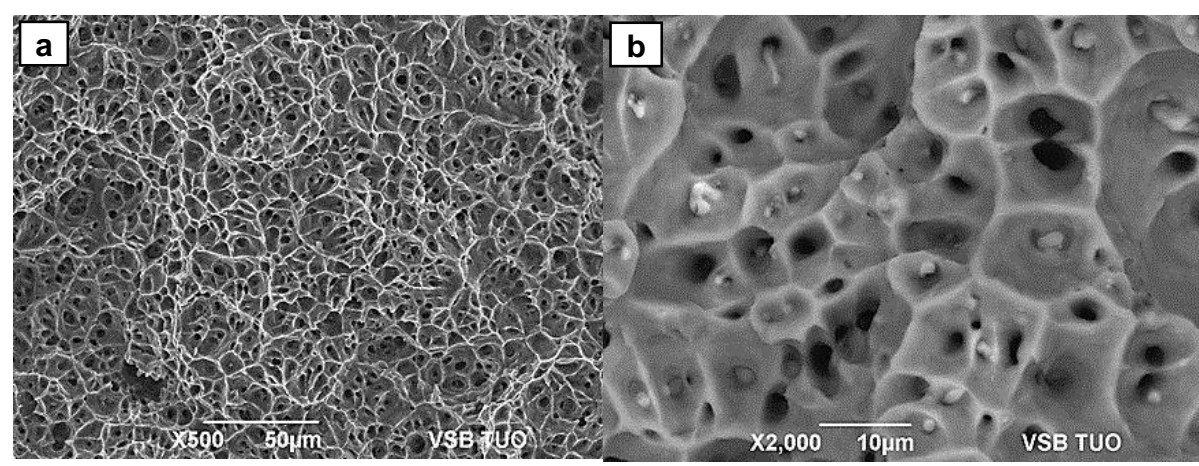

Figure 4 SEM image of fracture surface for the specimen 1 after tensile testing: a) surface with ductile dimples, b) detail of remaining phases observed in SEM BEI mode 
During the tensile testing, all specimens have been deformed with typical necking in the area of final rupture. As it can be seen in Figure 4a, fracture surface shows signs of ductile character with dimples and no visible grain boundaries which points out to ductile transgranular fracture. The image performed in backscattered electrons mode (SEM BEI) shows remaining phases inside the dimples which probably acted as initiation sites for the failure (Figure $4 b$ ).

Fatigue testing has been carried out using load control mode and symmetrical cycle of loading at five stress amplitudes with $20 \mathrm{~Hz}$ testing frequency. Used stress amplitudes were chosen in correlation with [1] to cover both LCF and HCF. Results of the tensile testing can be seen in Table 2.

Table 2Results of fatigue testing for A3003-H12 samples

\begin{tabular}{|c|c|c|c|}
\hline Specimen No. & $\boldsymbol{\sigma}_{a}(\mathrm{MPa})$ & Cycles executed & Result \\
\hline 2 & 76 & 9,991 & Fractured with necking \\
\hline 3 & 76 & 9,245 & Fractured with necking \\
\hline 4 & 76 & 7,551 & Fractured with necking \\
\hline 10 & 72 & 14,915 & Fractured with necking \\
\hline 11 & 72 & 38,813 & Fractured \\
\hline 12 & 72 & 36,563 & Fractured \\
\hline 13 & 70 & 39,211 & Fractured \\
\hline 14 & 70 & 77,193 & Fractured \\
\hline 1 & 68 & $2,754,924$ & Fractured \\
\hline 5 & 68 & 210,231 & Fractured \\
\hline 6 & 68 & $1,265,631$ & Unbroken \\
\hline 7 & 62 & $10,069,149$ & Unbroken \\
\hline 8 & 62 & $10,169,378$ & Unbroken \\
\hline
\end{tabular}

In the column of cycles executed some fluctuation of the results is evident. The widest range of values was obtained for the $68 \mathrm{MPa}$ stress amplitude. The most probable cause is some defect in the surface layer, which significantly reduced the time (number of cycles needed) for microcracks propagation for the sample 5 or 6 . Specimens tested at the highest stress amplitude (76 MPa) have been fractured with presence of necking similar to the tensile testing, without typical signs of fatigue on the fracture surfaces (Figure 5). The deformation of these samples reminds cyclic creep (ratcheting) even without the presence of nominal stress for which the ratcheting is typical [7].
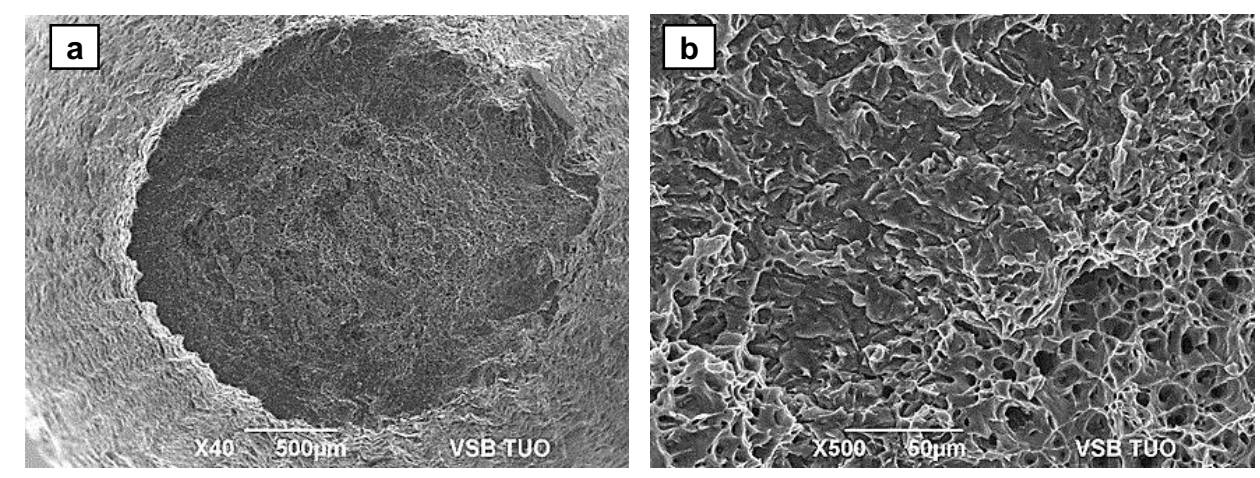

Figure 5 SEM fractography for the specimen 2 after fatigue loading at $76 \mathrm{MPa}$ : a) general view of the fracture surface, b) detail of the surface with two different mechanisms of crack propagation 
The stress amplitude level of $72 \mathrm{MPa}$ could be considered transitional as two results were obtained: one type of fracture was similar to the ones obtained at the highest stress level amplitude and the second type was typical fatigue fracture with radial steps, beachmarks, striations and final overload fracture (Figure 6).

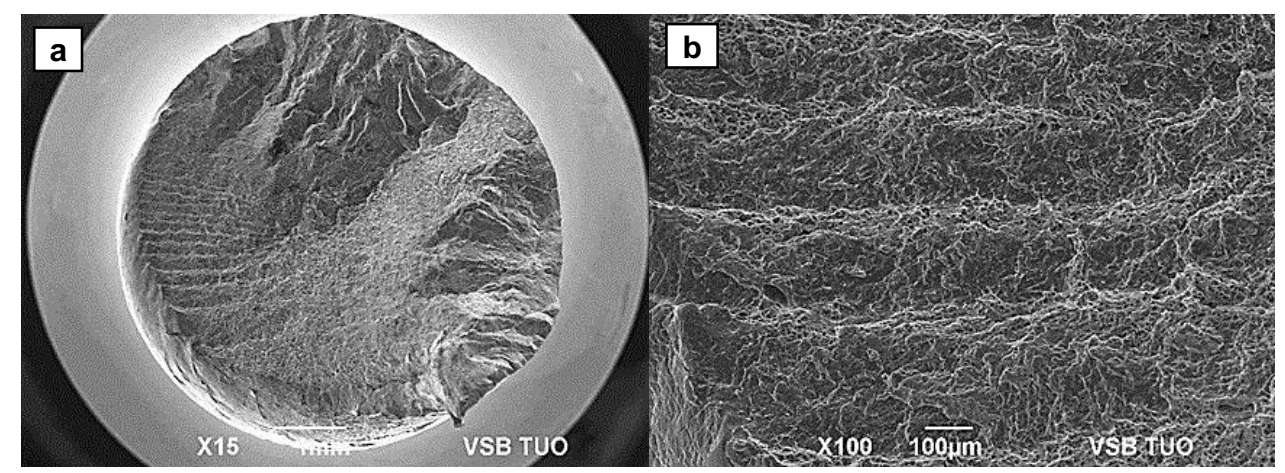

Figure 6 SEM fractography for the specimen 11 after fatigue loading at $72 \mathrm{MPa}(\mathrm{LCF})$ : a) general view of the fracture surface, b) detail of alternating crack propagation mechanisms

In this case, the $68 \mathrm{MPa}$ stress amplitude level could be considered as a transition from LCF to HCF with the number of cycles in magnitude of $10^{5}$ to $10^{6}$. Even though there is massive difference in the number of cycles, the fracture surfaces look very similar (Figure 7). This is in accordance with the theory behind the big difference in the number of cycles executed. While more than $90 \%$ of lifetime of the material during fatigue loading is consumed by microcracks propagation, the process of fatigue crack propagation after the initiation is relatively fast [8].

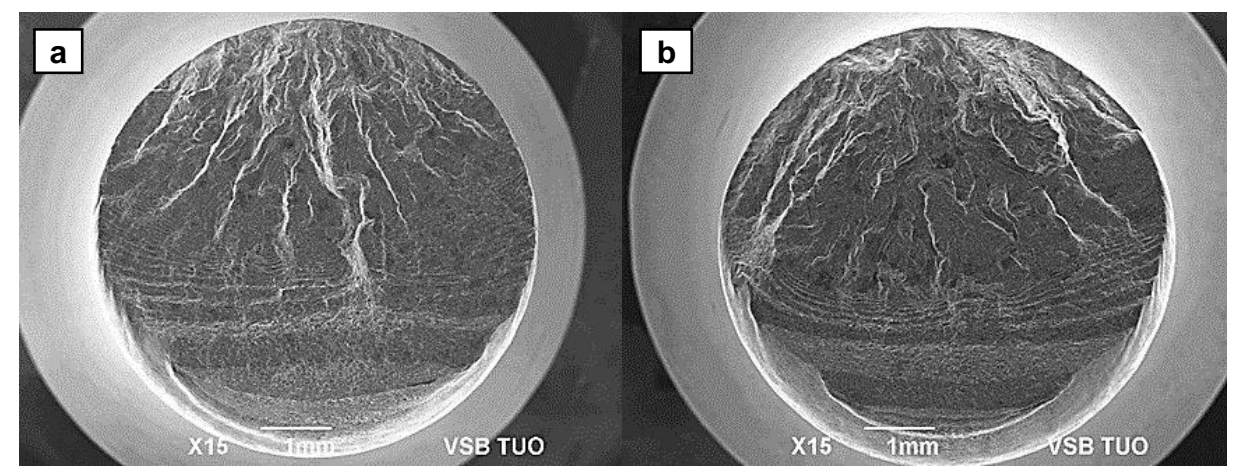

Figure 7 SEM fractography for the specimens after fatigue loading at $68 \mathrm{MPa}$ : a) specimen 1 (after $10^{6}$ cycles), b) specimen 5 (after $10^{5}$ cycles)

Important difference in fracture feature of the specimens loaded at $72 \mathrm{MPa}$ or $68 \mathrm{MPa}$ consists in ratio of ductile and brittle fields. Indeed, for the specimen loaded at higher stress amplitude the area of faster crack propagation with alternating mechanism of ductile/brittle crack propagation occupies bigger part of the surface and the individual marks are bigger and further away from each other. Testing on the lowest stress amplitude was ended after $10^{7}$ cycles without failure of the specimens, therefore in these conditions the stress amplitude of $62 \mathrm{MPa}$ can be considered as the fatigue limit for this alloy [9].Microhardness evaluation showed a trend of slight increasing hardness with increasing amount of deformation accumulated in the material. Nevertheless, the differences in microhardness are relatively small with average HV0.1 values of 48 and 43 for $\mathrm{H} 12$ and $F$ tempers, respectively. 


\section{CONCLUSION}

The study of the mechanical properties and microstructure was carried out for A3003-H12 alloy. The alloy was subjected to tensile and fatigue testing. During the tensile testing, specimens have been deformed with the presence of typical necking in the area of fracture. Values of the tensile strength obtained correspond with specifications of the alloy. During the fatigue loading (LCF) at $72 \mathrm{MPa}$ stress amplitude two results were obtained: first with deformation and necking of the specimen similar to the tensile testing and with no marks of fatigue on the fracture surface, second with typical fatigue fracture features. Lower stress amplitudes resulted in typical fatigue failures with initiation sites, radial steps, beachmarks, striations and final overload fractures. The main difference between the LCF and HCF fracture surfaces observed consisted in different proportions of the areas with different mechanisms of crack propagation. The lowest stress amplitude of $62 \mathrm{MPa}$ can be considered as fatigue limit of the alloy under these conditions as there was no damage observed even after $10^{7}$ numbers of cycles. Furthermore, the microstructure and microhardness of $\mathrm{H} 12$ and $\mathrm{F}$ tempers of the same alloy composition were compared. Microhardness values measured for both states showed increasing trend relating with thermo-mechanical treatment applied during material processing when $\mathrm{F}$ temper proved lowest hardness.

\section{ACKNOWLEDGEMENTS}

This work has been realized in the framework of the SGS project No. SP2021/62 "Materials based on non-ferrous metals - preparation, processes for improving their properties, area of application and the possibilities of recycling selected types of waste".

\section{REFERENCES}

[1] YAGUCHI, H. Fatigue-damage evaluation in aluminum heat-transfer tubes by measuring cell-wall thickness. Materials Science and Engineering. 2001, vol. 315, pp. 189-194.

[2] DU, Quiang. Microstructural modeling of the homogenization heat treatment for AA3XXX alloys. JOM. [online]. 2011, vol. 63, issue 7, pp. 35-39. Available from: https://doi.org/10.1007/s11837-011-0107-1.

[3] ALEXANDER, D.T.L. Solid-state intermetallic phase transformations in 3XXX aluminium alloys. Acta Materialia. 2002, vol. 50, pp. 2571-2583.

[4] ŠKODA, J. Study of fatigue fractures of AI-Mn alloy. In: IOP Conf. Ser.: Mater. Sci. Eng. Prague, 2019, pp. 461467.

[5] MAHMOODKHANI, Y. The development of grain structure during axisymmetric extrusion of AA3003 aluminum alloys. Metallurgical and Materials Transactions. 2015, vol. 46, issue 12, pp. 5920-5932.

[6] Atlas steels. Aluminium Alloy Data Sheet 3003. [online]. 2015, 1, 2 [viewed: 2021-05-07]. Available from: www.atlassteels.com.au

[7] SURAJIT, K.P. A critical review of experimental aspects in ratcheting fatigue: microstructure to specimen component. Journal of Materials Research and Technology. 2019, vol. 8, issue 5, pp. 4894-4914.

[8] MILELLA, Pietro Paolo. Fatigue and Corrosion in Metals. London: Springer, 2013.

[9] ASM 05224G. Elements of Metallurgy and Engineering Alloys. Materials Park, Ohio, USA: ASM International, 2008. 